Estudios Fronterizos, vol. 10, núm. 19, enero-junio 2009, pp. 119-156

\title{
De pueblo de misión a rancho frontereño: historia de la tenencia de la tierra en el norte de la Baja California, 1769-1861 ${ }^{1}$
}

\author{
Mario Alberto Magaña Mancillas*
}

Resumen. Como parte de las nuevas perspectivas historiográficas se considera pertinente volver al estudio de las historias de las instituciones o de los aspectos políticos de las sociedades en el pasado. Pero además cada vez es más importante la incorporación del análisis de las identidades colectivas en la historia, y uno de los caminos por los cuales podemos estudiar esos temas caros a la historia cultural es a través de la reconstrucción de la tenencia de la tierra de los propietarios durante los siglos XVIII y XIX en las regiones periféricas de la Nueva España y del México independiente. Este trabajo explora la ocupación y las formas de apropiación de los misioneros, soldados y rancheros en el norte de la Baja California en un periodo de poblamiento caracterizado por el establecimiento de pueblos de misión y después su transformación en ranchos frontereños. Conocer la historia de las disposiciones legales, contrastado con las formas de apropiación de las tierras misionales, nos permite esbozar una de las identidades más significativas de ese periodo y de la región: los frontereños.

Palabras clave: tenencia de la tierra, pueblos de misión, rancho frontereño, historia.

Abstract. In the new historiography is considered relevant to back the study of the history of institutions or the political aspects of societies in the past. But also it is increasingly important the analysis of collective identities in history, and one of the ways by which we can explore these themes to Cultural History is through reconstruction of the tenure of owners during the eighteenth and nineteenth centuries in outlying regions of New Spain and Mexico. This work explores the forms of occupation and ownership of the missionaries, soldiers and ranchers in northern Baja California over a period of the peopling characterized by the establishment of the Mission (pueblo de misión) and after its transformation into frontereños ranches. Knowing the history of the laws, but above all with contrasting forms of ownership of Mission lands, allows us to draw one of the most significant identities of that period and of the region: the frontereños.

Keywoords: land tenure, mission, frontereño ranch, history.

\footnotetext{
${ }^{1}$ Éste es un trabajo de exploración resultado de la investigación para el proyecto de tesis doctoral "Poblamiento e identidades en el área central de las Californias, 17691870 ", que se desarrolla en el Doctorado en Ciencias Sociales Tutorial del Colegio de Michoacán, bajo la dirección de la Dra. Chantal Cramaussel, y con apoyo del Conacyt. * Investigador del Centro de Investigaciones Culturales Museo. Universidad Autónoma de Baja California. El Colegio de Michoacán. Correo electrónico: mario_magana@yahoo.com
} 
Es importante señalar que este ensayo busca esbozar y comprender la historia de la ocupación occidental de las tierras del norte de la Baja California entre 1769 y 1861, siempre enlazada con la historia de los decretos emitidos - pero no necesariamente aplicados - sobre la tenencia de la tierra o la formalización de esa ocupación. En parte debido al interés despertado por la aportación pionera de David Piñera Ramírez (1991b), pero también como una forma de explorar las identidades históricas (Haas, 1995:9-10). Es de señalar que en la historiografía regional a veces se ha cometido el error de asumir que si un decreto o disposición reglamentaria fue emitida en la Ciudad de México o en las capitales regionales, tuvo una aplicación en los hechos y de manera inmediata en las regiones periféricas. En este ensayo se busca no caer en esa falacia, ya que se considera que la forma de reconocer o aplicar decretos y leyes por los grupos de poder locales puede auxiliarnos en la reconstrucción de los elementos de identidad que ayuden a esbozar sus posibles identidades colectivas (Giménez, 2004:77-99). Asimismo, se busca mostrar que el proceso de ocupación de la tierra explotable tuvo una estrecha relación con la gestión y desarrollo de los grupos de poder en la Alta California, especialmente hacia 1845-1846, antes de la invasión estadounidense al noroeste mexicano.

Se considera que se pueden encontrar elementos de identidad de los grupos sociales a través de la reconstrucción del proceso de posesión de las tierras y propiedades, ya que en los diferentes conflictos que se dieron en la región a mediados de esa centuria, se pueden observar referencias a los denominados "frontereños", ${ }^{2}$ que en su mayoría fueron rancheros y propietarios de ganados mayores. Por lo cual es que se propone la revisión de la historia de la tenencia de la tierra en el norte de la Baja California; y para una mejor exposición del devenir histórico y jurídico de la tenencia de la tierra, pero también vincu-

${ }^{2} \mathrm{El}$ término frontereño proviene de una referencia de la época y se refiere a la población no indígena del norte de la Baja California. Por ejemplo, “a los frontereños que ahora se hallan aquí huyendo, han presenciado los hechos y conocido los sujetos en la frontera, los he presentado al notario público para que depongan cuanto hayan visto [...]", Francisco del Castillo Negrete al ministro de Relaciones, San Diego, 9 de marzo de 1854 (León-Portilla y Muriá, 1992:173). 
lado al poblamiento, se sugiere dividir de manera instrumental el amplio periodo histórico de 1769 a 1861 en tres etapas intermedias: 1 . de 1769 a 1822, centrada en las tierras misionales y las mercedes a los soldados presidiales y misionales; 2. de 1822 a 1846, en la cual el eje fue el proceso de secularización; y 3. de 1846 a 1861, que se relaciona con la formalización de la ocupación y la especulación de las propiedades, motivadas por la cada vez mayor presencia de los gobiernos regionales y nacionales. Como comparación, para el caso de Sonora, Romero establece tres periodos que son: 1.1740-1769, relacionado con el antiguo régimen; 2. 1770-1829, con la política ilustrada y liberal; y 3. 1830-1860, con el estado de Sonora (Romero, 1995). Con relación a la Alta California, Robinson postula de manera indirecta dos grandes periodos: 1. 1784-1822, bajo el estilo colonial; y 2. 1822-1846, bajo la influencia de la secularización (Robinson, 1979:51-67).

\section{Tierras misionales y mercedes a soldados, 1769-1822}

Después de la expulsión de los jesuitas de la Antigua California (1767) y la llegada del gobernador Gaspar de Portolá con un contingente de soldados y posteriormente los franciscanos (1768), se dio inicio a una nueva circunstancia histórica en las Californias, destacando el impulso hacia el norte de la colonización novohispana. En un inicio se estableció una división entre las administraciones religiosas y temporales de las misiones peninsulares, la primera a los franciscanos y la segunda a los soldados comisionados, por lo que se puede plantear que los bienes misionales se consideraban comunales de propiedad de sus neófitos y que eran administrados por los soldados o por los misioneros.

Para el 12 de agosto de 1768, José de Gálvez "dio decreto para que los comisionados entregasen a los padres misioneros las temporalidades de las misiones para su económica administración" (Palou, 1994:34, y Gómez, 1993:622 y 625). Pero también en esa fecha el visitador real expidió una "Instrucción" que fue pieza angular para el posterior sustento legal de la adjudicación de tierras (Lassépas, 1995:61). Esta disposición era en realidad un reglamento de "las prerrogativas y condiciones indispensables con que a nombre del rey nuestro señor, concede mercedes de solares y suertes de tierra", y dirigido a nuevos 
pobladores. No obstante, poco detalla sobre la tenencia de la tierra para las nuevas fundaciones misionales que se realizaron a partir de 1769, aunque en el artículo segundo se estableció que "estos repartimientos de tierras se han de hacer sin perjuicio de los indios naturales, en soldados reformados, y en otros españoles de buenas costumbres". Lo que sí es de resaltar es que se percibe una fuerte referencia a que el poseedor último de los derechos a las tierras es el soberano, quien por su gracia concede el usufructo de la tierra a sus súbditos por convenir a los intereses de la corona, ya sea para el desarrollo y consolidación de las posesiones imperiales o el reconocimiento de ser súbditos tributarios (Lassépas, 1995:321-325).

Ahora bien, las principales fundaciones misionales, tanto de franciscanos como de dominicos, en el norte de la Baja California, se realizaron entre 1769 y 1797, siendo que de 1769 a 1794 se concentraron en consolidar la zona costera de la frontera misional y por consecuencia el conjunto de senderos que comunicaban a las misiones del sur con las del norte, y de 1794 a 1797 se dio un intento por reducir la frontera de gentilidad hacia la sierras conocidas hoy como Juárez y San Pedro Mártir, con las fundaciones de las misiones dominicas de San Pedro Mártir (1794) y de Santa Catarina (1797). Esta última orientada por el camino tradicional de comunicación de los valles intermedios con la zona del golfo y delta del Colorado, donde en 1781 se había cancelado por la oposición indígena un proyecto de colonización.

Salvo el presidio de San Diego establecido en 1769 y la fundación y corta vida de los pueblos con misión de las confluencias de los ríos Colorado y Gila en 1780 (San Pedro y San Pablo, y La Purísima Concepción) (Santiago, 1998), en el norte de la Baja California no se establecieron pueblos como en la Alta California, en donde se establecieron los de Nuestra Señora de los Ángeles, en 1781; San José, en 1797; y la villa de Branciforte, en 1797 (Lightfoot, 2005:58). Resulta interesante que mientras en la frontera del Gila y Colorado en 1781, se detuvo la incipiente colonización con el exterminio de los nacientes poblados, en la zona costa del Pacífico de la Alta California se fundó un nuevo pueblo; y mientras en 1797 en el norte de la Baja California se avanzaba de manera tímida hacia las regiones de la sierra y hacia el camino 
del desierto y delta del Colorado, en el norte de la Alta California se fundaron dos pueblos con misión y con nuevos colonos: San Rafael, 1817, y San Francisco Solano, 1823 (Lightfoot, 2005:155-156 y 200-201).

Además de las fundaciones misionales realizadas en la región con sus congregaciones y sus tierras de cultivo, el caso más temprano y al parecer único de dotación de tierras en el norte de la Baja California fue a favor del alférez José Manuel Ruiz, quien lo había solicitado en 1804. Ruiz recibió del gobernador José Joaquín de Arrillaga dos sitios de ganado mayor en el denominado "paraje de la ensenada de Todos Santos" en 1805 (Martínez, 2001:66), que equivalen a aproximadamente 3494 hectáreas a una conversión de 1747 hectáreas por sitio (Radding, 1997:177). Asimismo obtuvo los consentimientos de los misioneros de San Miguel y de Santo Tomás, de las dos misiones más cercanas a la concesión. Recuérdese que la de Nuestra Señora de Guadalupe del Norte se fundó en 1834, y sería la más inmediata desde una perspectiva actual. No obstante, al parecer desarrolló poco los terrenos asignados, salvo el uso para pastoreo del ganado, ya que para el año de 1822, el citado propietario estaba residiendo primero en la misión de San Vicente y luego en el poblado de Loreto, donde se hizo cargo del gobierno peninsular (Lassépas, 1995:204; Piñera, 1991a:120-123; Treviño, 1982:47). Posteriormente, en 1821, trasladó sus derechos a su yerno Francisco Xavier Gastélum, quien ocupó el predio fundando el rancho de La Ensenada (Martínez, 2001:66; Piñera, 1991a:120-123). Coincidentemente, en 1823 se estableció el primer rancho en el área del actual San Diego, Los Peñasquitos, otorgado al capitán Francisco María Ruiz, hermano del alférez José Manuel Ruiz (Pourade, 1966:11; Martínez, 2001).

En general, poco se avanzó en materia evangelizadora en la reducción de la frontera de gentilidad hacia las sierras interiores y la zona oriental del norte de la Baja California (hacia el golfo de California, el delta y parte sur del río Colorado, lo que en la actualidad es delimitación estatal entre California y Arizona), pero también en la formación de ranchos privados, salvo el de José Manuel Ruiz en la ensenada de Todos Santos, concedida en 1805, pero con un uso eminentemente ganadero por lo menos hasta 1824 . 


\section{Ocupación y secularización, 1822-1846}

Con el proceso de decaimiento de las misiones del norte de la Baja California que se inició alrededor del ciclo 1808-1810, pero que es notorio desde una perspectiva contemporánea hacia el año de 1818 cuando se abandonaron las misiones de San Francisco Borja y San Fernando Velicatá, ${ }^{3}$ que facilitaban la comunicación terrestre entre la Antigua California (vía San Ignacio) y el norte de la Baja California (vía Nuestra Señora del Santísimo Rosario), los pobladores fortalecieron e intensificaron sus actividades agropecuarias con base en el aprovechamiento de las tierras roturadas por los misioneros, los soldados misionales y los neófitos, fundando ranchos particulares. Como lo describe Peveril Meigs, "a medida que decaían los ranchos [...] de las misiones, y cuando las propias misiones fueron secularizadas, una parcela tras otra fue cayendo en manos privadas [...] El periodo de los ranchos privados estaba ya bien encaminado antes de que la última misión fuese abandonada en 1849" (Meigs, 1994:272).

Estas propiedades privadas eran de tipo principalmente ganadero, basados en la autosuficiencia familiar precaria, con una cultura rudimentaria ligada a la supervivencia en una zona ecológicamente hostil para los estándares occidentales, que debido a su situación propició un acercamiento cultural con los indígenas colindantes, primero con los cristianizados y después con los no cristianizados o gentiles. Esto parece que se presentó principalmente después de la década de los años veinte del siglo XIX, cuando los nuevos propietarios empezaron a estructurar y hacer económicamente rentables los antiguos predios misionales. Los nuevos, o mejor dicho incipientes rancheros buscaron ocupar los sitios de labor dejados por los misioneros y sus indígenas cristianizados, en algunos casos despojándolos de tierras y en otras conviviendo con ellos, pero es de insistir en que no fueron nuevos colonos, sino los propios soldados misionales, mayordomos, sirvientes, sus familias y sus descendientes.

\footnotetext{
${ }^{3}$ De las misiones que hoy se ubican en el actual estado de Baja California, Calamajué se abandonó en 1767, Santa María de los Ángeles en 1768, San Francisco Borja y San Fernando Velicatá en 1818 y Santa Gertrudis en 1822 (Mathes, 1977; Vernon, 2002).
} 
Es de señalar que mientras en la Alta California las misiones estaban no sólo activas sino con un desarrollo importante al momento de la secularización (1833), en el norte de la Baja California estas comunidades se encontraban, en su mayor caso, en decadencia o abandonadas. En el año de 1797 se dio el mayor avance dominico con la fundación de San Miguel Arcángel, y no se realizó ningún nuevo desarrollo misional como tal. Así, para 1818 fue cerrada la misión de San Fernando Velicatá y para 1834 tan sólo mantenían cierta actividad, con dos o tres misioneros en total, las misiones dominicas de Santo Domingo, Santo Tomás y Santa Catarina, fundándose la última "misión dominica", la de Nuestra Señora de Guadalupe del Norte, que realmente se instaló bajo las necesidades administrativas del ranchero y padre presidente fray Félix Caballero. ${ }^{4}$ Para los años de 1839-1840 fueron abandonadas Santo Domingo, Santa Catarina y la de Guadalupe del Norte, quedando una misión: Santo Tomás, la cual fue cerrada oficialmente hasta el año de 1849, aunque el misionero fray Tomás Mansilla permaneció como capellán de la colonia militar posiblemente hasta principios de 1851 (AD-IIH, Justicia y Negocios Eclesiásticos, 4.59, f. 1-3).

Se propone que el año de 1822 es crucial en cuanto a la concesión de tierras en las Californias, no sólo por la jura de la Independencia que se realizó en diversos puntos de esta amplia región (Ortega, 2001:241; Del Río y Altable, 2000:95; Martínez, 2002:170), sino por la llegada del comisionado imperial, el canónigo Agustín Fernández de San Vicente, primero a Loreto hacia junio de 1822, donde hizo jurar la Independencia y nombró nuevo gobernador en la persona de Fernando de la Toba (Del Río y Altable, 2000:96), y después al norte, permaneciendo en San Diego hasta noviembre de 1822 (Piñera y Ortiz, 1989:28-29). Durante su estancia, en julio de 1822, Fernández expidió la primera disposición formal y específica sobre el futuro de las tierras misionales de las Californias, titulada "Reglamento provisional que debe regir por ahora en las misiones de la Baja California".

\footnotetext{
${ }^{4}$ Para 1830 se encontraban funcionando en el sur de la península las misiones de San Ignacio, Todos Santos y San José del Cabo, las cuales fueron clausuradas en 1840 (Mathes, 1977; Vernon, 2002).
} 
En general, lo que estipula este Reglamento de 1822 es que los misioneros son los responsables temporales de los bienes misionales "hasta que el gobierno disponga lo que tenga a bien, en orden a las responsabilidades de dichas misiones", pero además

[...] para que los nuevos ciudadanos entiendan [es decir los indios de las misiones] que el actual sistema no es una mera teoría y libro insignificante, que se les dé su ración a cada uno, y que si en otra parte se les proporcionan mayores ventajas, se les permita usar del derecho que tienen por la ley, para poder disfrutar de aquella comodidad, que no les puede facilitar su misión (Lassépas, 1995:325-327).

Lo que se percibe es un espíritu de política de emancipación de los indios de las misiones, más que un principio de secularización de las misiones para aprovechar sus tierras, aunque no se puede negar que ambos aspectos corresponden a un mismo proyecto de liberación de las tierras y la fuerza de trabajo para el impulso de la colonización de las periferias de la naciente nación.

Con base en el citado reglamento, se iniciaron las adjudicaciones de tierras en diversos puntos de la Baja California, especialmente en el sur, y resalta que de las 183 enajenaciones que Ulises Urbano Lassépas logró documentar hasta finales de 1857 y principios de 1858, 20.22\% las adjudicó Ruiz en su periodo administrativo (1822-1825), siendo el que más concesiones otorgó (35 títulos que comprendían 37 sitios de ganado mayor, unas 64639 hectáreas). El funcionario que le sigue en número de concesiones es Rafael Espinoza (1849-1853) con 16.39\% (30 título con 34 sitios). Aunque con relación a las extensiones de las concesiones, es de destacar a José María Gómez (quien gobernó en 18551856) con $7.65 \%$ de los título (14), pero que representaban 36 sitios de ganado mayor. Así, mientras con Ruiz cada título representaba 1.06 sitios de ganado mayor en promedio, con Espinoza la relación fue de 1.13 sitios por título, y con Gómez esta relación se incrementó a 2.57 sitios por cada concesión de tierras (Lassépas, 1995:242).

Por su parte, al gobernador Ruiz también le tocó conocer la Ley General de Colonización que expidió Guadalupe Victoria el 18 de agosto de 1824 (Lassépas, 1995:204), la cual, según la opinión de Lassépas, 
"ha dominado siempre [para 1857] a las otras que han tratado de la misma materia; ha atravesado nuestras décadas revolucionarias, algunas veces maltratadas, casi siempre en su fuerza y vigor" (Lassépas, 1995:65-66). En la Alta California, para Robinson, estimuló el establecimiento y satisfizo las demandas de los promotores mexicanos de posibles movimientos colonizadores (Robinson, 1979:65). Lo importante de esta ley son los artículos $2^{\circ}$ y $16^{\circ}$, que respectivamente señalan: "Son objeto de esta ley aquellos terrenos de la nación, que no siendo de propiedad particular ni pertenecientes a corporación alguna o pueblo, pueden ser colonizables", y "El gobierno, conforme a los principios en esta ley, procederá a la colonización de los territorios de la república" (Lassépas, 1995:328-330). Para llevar a cabo lo anterior era necesario la elaboración del reglamento específico (sobre todo por el artículo $16^{\circ}$ ), el cual fue publicado hasta el 21 de noviembre de 1828 cerca de cuatro años después, bajo el título de Reglamento para la colonización de los territorios de la República (Lassépas, 1995:205-206 y 334-338; Robinson, 1979:65; Ortega, 2001:265). Sin embargo, lo interesante es que en el tiempo intermedio que no existió este reglamento se buscó aplicar la Ley General de Colonización, salvando el impedimento de la falta de las regulaciones específicas por parte del supremo gobierno con instrumentos expedidos en las Californias, como los decretados por José María Echeandía entre 1825 y 1826.

Es de recordar que Echeandía fue nombrado Jefe Político de las Californias y llegó a Loreto para junio de 1825, y ya desde su nombramiento se le había instruido de que llegando a su destino procurara "adquirir verdaderos y seguros conocimientos de las calidades del terreno", pero sobre todo "el estado en que se halla el repartimiento de tierras; cuales son las que ocupan las misiones; si hay baldíos, sobre su calidad y extensión; qué número de personas de los pobladores e indios tienen capacidad de cultivar por sí mismos". Pero además se le recomendó que "con los neófitos y catecúmenos se acomodará por ahora al sistema de misión mientras no se establece otro más adecuado" (AD-IIH, Gobernación, 2.4, f. 5-9).

Así, según Lassépas, cuando llegó Echeandía consultó "con los nuevos misioneros dominicos que lo han acompañado desde México, el mejor modo de repartir entre los indígenas las tierras baldías de la 
comprensión de ciertas misiones" (Lassépas, 1995:204-205). Sin embargo, no se ha podido esclarecer si éstos tuvieron influencia en el nuevo gobernador. Pero para agosto de 1825 Echeandía expidió el Reglamento para el reparto de las tierras de las misiones de San Francisco Javier, San José Comondú, La Purísima, Mulegé, San Ignacio, Santa Gertrudis, San Francisco de Borja, San Fernando y El Rosario (Lassépas, 1995:330334; Trejo, 2002:169). Sin embargo, con relación al norte de la Baja California, se especificó que se exceptuaron "a la de San Miguel que merece la consideración que distingue a la de la Nueva California y las de Santo Domingo, San Vicente, Santo Tomás y Santa Catarina, por si acaso con sus respectivos padres cada una pueda prosperar" (Lassépas, 1995:331).

Hacia octubre de 1825, el propio Echeandía despachaba desde el puerto de San Diego y después desde Santa Bárbara, en la Alta California (Lassépas, 1995:205; Engelhardt, 1929:665), donde permaneció por lo menos hasta principios de 1827. Así, en ese periodo, el 25 de julio de 1826 expidió el Plan de secularización y decreto de emancipación en las misiones de la Alta California (Ortega, 2001:278-279; Robinson, 1979:29). Para Sergio Ortega Noriega, con estas disposiciones, "de acuerdo con los frailes, se puso en práctica la emancipación parcial de los indios al eximirlos de la tutela de los religiosos, aunque éstos conservaban la administración de las misiones [Pero] no se sabe cuál fue el efecto práctico de esta emancipación" (Ortega, 1993:165). Por su parte, para Martha Ortega sí tuvo un impacto importante, sobre todo porque se realizó una liberación de los indios de las misiones, especialmente los neófitos mayores de 15 años, bautizados y que pudieran demostrar que sabían labrar tierras cultivables. No obstante, la medida fue contraproducente ya que los indígenas emancipados no regresaron a trabajar ni a las misiones ni a los ranchos ni a los pueblos circunvecinos, por lo que Echeandía trató de dar marcha atrás a estas disposiciones y los indios fueron compelidos a regresar a las misiones, con poco éxito (Ortega, 2001:278).

Por su parte, el supremo gobierno en la Ciudad de México lograba dar forma al reglamento necesario para la implementación de la citada Ley General de Colonización de 1824, con la publicación del citado Reglamento para la colonización de los territorios de la República (21 de no- 
viembre de 1828) (Lassépas, 1995:335). Dos son los puntos fundamentales de esta disposición reglamentaria: el artículo $1^{\circ}$ que concedió a los jefes políticos la autoridad para que "puedan conceder terrenos baldíos de sus respectivos territorios, a los empresarios, familias o personas particulares mexicanas o extranjeras que los soliciten, con el objeto de cultivarlos o habitarlos", y el artículo $17^{\circ}$ en que se estableció que "en los territorios en que haya misiones, los terrenos que éstas ocupen, no podrán colonizarse por ahora y hasta que se resuelva si deben considerarse como propiedad de las reducciones de los neófitos, catecúmenos y pobladores mexicanos" (Lassépas, 1995:334-338). No obstante esta última disposición, las autoridades de las Californias, tanto el jefe político Echeandía (Alta California) como el jefe político subalterno José Mariano Monterde (Baja California), implementaron estrategias encaminadas a enajenar las tierras misionales.

En el caso de la Alta California, la diputación territorial emitió entre el 29 de julio y el 30 de agosto de 1830, el "Plan para convertir en pueblos las misiones de la Alta California (1828)", en el cual se estipulaba que las tierras y ganados de las misiones serían repartidas entre los neófitos mayores de 25 años de edad o de 18 si fueran casados, que dichas tierras no podrían ser hipotecadas ni enajenarse a terceros, que los misioneros quedaban en calidad de párrocos, y se iniciaría el plan convirtiendo las misiones de San Gabriel y la de San Carlos Borromeo en los primeros pueblos de misión secularizados. En cuanto a las restantes, les serían asignados administradores o mayordomos con el objetivo de que en un corto plazo todas fueran convertidas en pueblos. Con base en esta disposición y como complemento, Echeandía expidió el 6 de enero de 1831 el Decreto de la secularización de las misiones que también había sido formulado por la diputación territorial, y para el 18 de noviembre de 1832 publicó el Reglamento de secularización (Ortega, 2001:266, 278-279 y 333).

Por su parte, en la Baja California, en septiembre de 1830, el jefe político Monterde expidió un reglamento donde se estableció, en su primer artículo, la extinción de las misiones de San José del Cabo, Todos Santos, San Francisco Javier, San José Comondú, Santa Rosalía Mulegé, Concepción de Cadegomó, San Ignacio, Santa Gertrudis y San Francisco de Borja. El propósito era convertirlas en pueblos y no su eliminación 
por completo, además que se estipuló que "las tierras serán repartidas entre los indígenas a proporción de lo que cada uno pueda cultivar" $\left(\right.$ artículo $3^{\circ}$ ). Ahora bien, para el norte de la Baja California, Monterde escribió en este reglamento en los artículos $6^{\circ}$ y $14^{\circ}$ que:

Quedan por ahora con el carácter de misiones, San Fernando [en realidad abandonada desde 1818], El Rosario, Santo Domingo, San Vicente, Santo Tomás, San Miguel y Santa Catarina, por tener a su cargo un número considerable de catecúmenos [...] 14 . Quedan por ahora con el carácter de misiones, todas las de Fronteras por tener aún conquista viva y número considerable de neófitos (Lassépas, 1995:339-340).

En cuanto a concesiones de tierras en el norte de la Baja California posteriores a 1822, se cuentan el ya citado rancho La Ensenada que había sido traspasado por cesión de José Manuel Ruiz a su yerno Francisco Xavier Gastélum en 1824 (Velasco, 1893:2). Por su parte, José Manuel Machado era propietario del rancho El Rosario, que según The San Diego Union, del 7 de marzo de 1874, "le fue otorgado en propiedad el 14 de febrero de 1827, por el gobernador José María Echeandía, con una extensión de once leguas" (citado por Ortiz, 1989:45). Asimismo, para 1829 ese mismo gobernador concedió el rancho de La Tijuana o Tía Juana a Santiago Argüello (Piñera y Ortiz, 1989:31; AM-IIH, rollo 7, pp. 104-105), y su hijo Santiago Emigdio Argüello recibió en 1833 del gobernador de la Alta California, José Figueroa, el rancho Milijó o Melyo en el área de San Diego (Padilla, 2007:164; Ortega, 2001:269, cuadro 28).

Mientras, en la Alta California para febrero de 1833 llegó el nuevo gobernador Figueroa, quien intentó por instrucciones del supremo gobierno modificar las acciones locales sobre la secularización de las misiones impulsadas por Echeandía, procurando proteger los bienes de las misiones con la idea de que los neófitos fueran los primeros en poder disfrutar de ellos (Ortega, 2001:266-267 y 334). Con este fin promulgó dos disposiciones legales: el 15 de julio de 1833, las “Prevenciones provisionales para la emancipación de los indios reducidos en las misiones de la Alta California", y el 9 de agosto de 1833 un "Reglamento provisional" (Ortega, 2001:267, 279 y 334). Además de otorgar 
el rancho de Tecate a Juan Bandini el 14 de diciembre de 1833 (Romero, 1990:55-56).

Al mismo tiempo, para el 17 de agosto de 1833, desde la Ciudad de México Valentín Gómez Farías promulgó el Decreto de secularización de las misiones de la Alta y la Baja California, el cual se conoció en la Baja California por un bando expedido en La Paz, nueva capital territorial, el 26 de septiembre de 1833 por Monterde (Lassépas, 1995:340-343). Pero en el caso de la Alta California, como lo señala Ortega, "en octubre [de 1833], la ley fue adoptada por los californios pero sin aceptar una serie de medidas que el gobierno de Gómez Farías había promulgado en torno a ella" (Ortega, 2001:267). Principalmente destaca la interpretación que realizaron los principales líderes de la Alta California de que las tierras serían repartidas entre los neófitos y las sobrantes entre colonos que no residieran en las antiguas misiones, que creyeron que serían colonos traídos desde el centro de la nación mexicana (Ortega, 2001:335-336 y 346).

Además de que el propio Figueroa, después de su llegada y al estudiar la situación, más tarde concluyó que la secularización era inevitable (Ortega, 2001:334), y más que acatar el decreto federal del 17 de agosto de 1833, realizó una interpretación del mismo y ante la supuesta falta de la reglamentación respectiva, la diputación territorial decretó el 9 de agosto de 1834 el Reglamento provisional para la secularización de las misiones de Alta California, y el 3 de noviembre de 1834 el Reglamento de misiones secularizadas, que se aplicaría para las primeras diez misiones afectadas.

En cuanto al Reglamento provisional, éste permitió continuar con la secularización altacaliforniana más que iniciarla, como se ha establecido en la historiografía regional al suponer que el detonante del proceso fue el decreto del supremo gobierno del 17 de agosto de 1833. Este reglamento regional permitió que el jefe político aplicara la secularización en diez misiones en un primer momento y luego a las restantes, reconociendo que San Juan Capistrano se daba por secularizada,

\footnotetext{
${ }^{5}$ Existía un borrador de la propuesta legislativa fechado el 13 de abril de 1833, pero los articulados no sufrieron cambios (AD-IIH, Gobernación, 4.22, f. 1-2; AD-IIH, Archivo General de la Nación, 1.45). El decreto fue publicado el 20 de agosto de 1833 (AD-IIH, Dublán y Lozano, 1.11).
} 
y así "el gobierno territorial se haría cargo de las temporalidades de las misiones, ganado y toda clase de implementos y herramientas, serían distribuidos entre los neófitos, el remanente quedaría bajo la administración de un mayordomo" (Ortega, 2001:336). Es decir, que los grupos de poder locales podrían controlar la adjudicación de los bienes misionales secularizados.

Así, todas estas disposiciones legales emitidas por la diputación territorial de la Alta California y apoyadas por el gobernador Figueroa buscaban la liberalización de las tierras misionales y de la fuerza laboral indígena relacionada con las misiones, para el aprovechamiento por sus supuestos dueños, es decir los neófitos, pero en realidad se referían a los californios, y siempre en oposición a que las ocuparan personas ajenas a las regiones de la Alta California (Ortega, 2001:337338). Para el 7 de noviembre de 1835 las autoridades nacionales intentaron desde la Ciudad de México suspender la secularización de las misiones de la Alta California, pero hubo oposición de los californios y faltó una autoridad local que la impulsara además de que, en efecto, para ese año ya eran 16 las misiones a cargo de comisionados, ya fuera como administradores o mayordomos. En realidad, poco se podía revertir, más bien inició un proceso de expansión de la secularización altacaliforniana hacia el norte de la Baja California.

Por su parte, el jefe político de la Baja California, Luis del Castillo Negrete, promulgó el 25 de agosto de 1838 una "Instrucción para facilitar y obtener los títulos de propiedad de tierras colonizables y baldías" que se basa en el artículo $1^{\circ}$ del Reglamento para la colonización de los territorios de la República del 21 de noviembre de 1828, y por tanto buscaba reglamentar el procedimiento de las solicitudes de concesiones y los títulos de propiedad de tierras en su jurisdicción (Lassépas, 1995:344-348; Trejo, 2002:169). Asimismo, el 11 de julio de 1840 Castillo Negrete también expidió el decreto Colonización. Bienes raíces de las ex misiones. El punto fundamental de esta disposición está en el artículo $1^{\circ}$, que aunque breve, rotundo: "Que donde no hay comunidad de neófitos no hay misión". Aunque obvio, vino a romper la posesión de fray Gabriel González sobre las tres misiones sobrevivientes en el sur de la península, sobre todo la de Todos Santos, básicamente un rancho particular para ese entonces, y de ahí la revuelta que impulsó el 
misionero por esas fechas y que sólo impactó el extremo sur peninsular (Landavazos, 2003:272-274).

No obstante del citado artículo, Castillo Negrete en su declaratoria inicial al decreto sostuvo que se debía aplicar en todas las misiones o antiguas misiones, "a excepción de las de Fronteras que son las únicas misiones que han existido hasta hoy". Pero además, resultan interesantes sus razonamientos o exposición de motivos, sobre todo el que señala que "teniendo en consideración que las tierras pretendidas han estado en poder de los reverendos padres ministros actuales de estas fenecidas misiones, no en propiedad sino en usufructo, y no por disposición legal, sino por tolerancia y contemplación", y de ahí que en los artículo $2^{\circ}$ y $3^{\circ}$ decretara que "los bienes raíces de las fenecidas comunidades de neófitos por derecho de reversión, pertenecen a la repúbli$\mathrm{ca}^{\prime}$, y por tanto que "tales bienes son nacionales colonizables" (Lassépas, 1995:350 y 351. Énfasis añadido).

En general, para el inicio de la década de los años cuarenta del siglo XIX, tanto en la Alta como en la Baja California el proceso de secularización estaba operando con el apoyo de los grupos locales que en ambos casos buscaron ser los beneficiarios de las concesiones. Pero además, para impedir que colonos fuereños o más allá del antiguo noroeste novohispano pudieran aprovechar las circunstancias, se fue estructurando un discurso de defensa de los derechos de los neófitos a los bienes misionales, principalmente las tierras aprovechables, pero también del ganado, y que en parte se transformó en un discurso nativista (Ortega, 2001:339).

\section{Formalización y especulación, 1846-1861}

Esta estrategia impulsó el fortalecimiento de los grupos de poder en la Alta y la Baja California, siempre buscando obtener los mejores recursos y beneficios, y en el caso de los de la Alta California, gestando un incipiente deseo expansionista que afectó al norte de la Baja California. Así, desde el gobierno de Figueroa, los gobernadores utilizaron los nombramientos de administradores y mayordomos de las misiones en proceso de secularización como formas de establecer alianzas políticas, económicas y sociales (Ortega, 2001:351). Tal es el caso de Pío 
Pico, quien fuera nombrado administrador de la antigua misión de San Luis Rey desde 1834, y que se aprovechó de esta circunstancia para abusar de los neófitos hasta el punto de que éstos se negaron a trabajar, además de comerciar las telas para la vestimenta de los indios con extranjeros (Ortega, 2001:381 y 387).

En general, tras la muerte del gobernador Figueroa el 29 de septiembre de 1835, hasta la invasión estadounidense iniciada el 7 de julio de $1846,{ }^{6}$ en la Alta California se vivió un continuo enfrentamiento entre los grupos de poder centrados en el norte con el puerto de Monterrey, la capital oficial, y en el sur con el pueblo de Nuestra Señora de los Ángeles. Por su parte, el gobierno mexicano intentó controlar a esta parte de la nación mexicana con el envío de gobernadores como Mariano Chico (1836) o Manuel Micheltorena (1842-1845), con muy pocos resultados. Sobre todo en el caso de Micheltorena, quien llegó con unos 600 soldados que fueron vistos por los habitantes de la Alta California como posibles colonos que les podrían disputar las antiguas tierras misionales aún no concedidas (Piñera y Ortiz, 1989:36). Pero además este gobernador expidió en 1843 el Decreto por el cual devuelve la administración de misiones a los frailes (Ortega, 2001:346-347; Engelhardt, 1929:664; Lassépas, 1995:208). Lo que indudablemente motivó que se organizara una revuelta en su contra con el apoyo de ambos grupos de poder de la Alta California, y tras la batalla de Cahuenga, cerca del pueblo de Nuestra Señora de los Ángeles, el propio Micheltorena tuvo que capitular y estuvo de acuerdo en abandonar la región junto con sus "cholos", como se les denominaba a sus tropas.

Después de lo cual, los grupos de poder decidieron que se nombraran a Pío Pico como gobernador interino, a José Castro como coman-

\footnotetext{
${ }^{6}$ Tras la firma del Tratado de Guadalupe-Hidalgo (1848), de la incorporación de la Alta California a los Estados Unidos de América (1850), y del Acta de Tierras de 1851 expedida por el Congreso Federal de los Estados Unidos, se requirió definir por la necesidad jurídica de interpretación de estos acuerdos, a partir de qué momento fue que los Estados Unidos tuvieron el control de la Alta California y por tanto, cualquier decreto de los gobiernos locales, regionales o nacionales mexicanos dejaron de tener valor jurisdiccional. Así, la Suprema Corte de Justicia decidió que esa fecha clave o mojonera temporal sería el 7 de julio de 1846, cuando el comodoro John D. Sloat tomó posesión del puerto y el área cercana a Monterrey (Robinson, 1979:69, 101 y 105).
} 
dante militar, y Juan Bandini fue designado secretario del gobernador (Pourade, 1966:57-58; Pío Pico, "Narración histórica", en BL, CD, vol. 13:131). Del grupo de los sur de la Alta California, los de San Diego eran un fuerte pilar, encabezados por Juan Bandini, rico ranchero de esta zona, y su protegido Pío Pico (Castillo y Ríos, 1989:119). Pico fue gobernador del 22 de febrero de 1845 hasta el 10 de agosto de 1846, teniendo sus oficinas gubernamentales en el pueblo de Nuestra Señora de los Ángeles (Engstrand, 1980:30), y favoreció a su grupo, pero especialmente a los rancheros del área de San Diego, como Juan Bandini, Santiago E. Argüello, Juan Machado y Tomás Warner, entre otros.

Según Robinson, son tres las disposiciones legales emitidas en ese periodo: a) el "Decreto del 28 de mayo de 1845 ", sobre la renta y conversión de las misiones y emitido por la Asamblea Departamental; $b$ ) las "Regulaciones" del 28 de octubre de 1845 que fueron promulgadas por Pico como gobernador para aplicar el anterior decreto (AD-IIH, Gobernación, 6.53, f. 2); y c) el "Bando-Autorización del 3 de abril de 1845", decretado por la Asamblea Departamental, también sobre la venta de las misiones (Robinson, 1979:67). Así, en 1845 la Junta Departamental de la Alta California, con Pico a la cabeza, "decidió que las tierras que quedaban en las misiones se vendieran y de no ser así, el gobierno las rentaba por nueve años a quien deseara ocuparlas. Se acordó que un tercio de esa renta fuera para los neófitos. Desde ese momento los nativos tuvieron que pagar por obtener los títulos de propiedad de sus terrenos" (Ortega, 2001:351-352).

Es en este breve periodo (1845-1846) que se presenta evidencia de que el proceso de consolidación del grupo de poder de la Alta California, especialmente el de los "sureños", se fue desarrollando con un intento expansionista hacia el norte de la Baja California. Sin embargo, para el 13 de mayo de 1846 el presidente de los Estados Unidos de América, James Polk (1845-1849), declaró la guerra a la República Mexicana; para el 7 de julio el comodoro John D. Sloat tomó posesión del puerto de Monterrey, capital oficial del departamento de las Californias, ${ }^{7}$ y el 29 de julio se tomó el pueblo de San Diego (Robinson,

\footnotetext{
${ }^{7}$ Desde una perspectiva de las disposiciones surgidas por los poderes del supremo gobierno mexicano, tanto la Baja como la Alta California pudieran ser entendidas como una unidad administrativa, ya que desde la Sexta Ley Constitucional
} 
1979:69, 101 y 105; Pourade, 1966:71 y 79). A la vez se inició una lucha de resistencia por parte de los californios, sobre todo de algunos de los "sureños". No obstante, ante la toma del pueblo de Nuestra Señora de los Ángeles el 10 de agosto de 1846, que era la sede del gobierno departamental, Pío Pico y José Matías Moreno iniciaron su huida hacia el sur por la península, llegando al puerto de Mulegé el 22 de octubre, después de seis semanas de travesía. Algunos autores señalan que José Castro los acompañó y después siguió hacia Sonora (Castillo y Ríos Bustamante, 1989:137), otros indican que a Pico y a Moreno los acompañaba Macedonio González (Pourade, 1966:84-85; Pío Pico, "Narración histórica", en BL, CD, vol. 13:164-165).

De este viaje se fue conformando el supuesto de la adjudicación de tierras en el norte de la Baja California por Pío Pico, mediante la realización de subastas con las cuales se procuró de fondos para el viaje, y que fue muy difundido en diferentes reportes realizados en la segunda mitad del siglo XIX, y que después fue repetido en la historiografía regional por la influencia del memorial de Lassépas. Por ejemplo, en 1853 Francisco del Castillo Negrete informaba que

[...] la intensión del gobernador [Pío Pico], según unos, fue la de arbitrarse recursos para sostener la guerra contra los americanos; pero esto no tuvo efecto porque el gobernador se retiró del país, y sólo de uno de los agraciados hay constancia que pagó [José Luciano Espinosa de Santo Domingo] y que el ministro de Santo Tomás [fray Tomás Mansilla] dispuso del dinero en su provecho. Según otros, fue la intensión del gobernador agraciar a mexicanos, creyendo que se perdería también la Baja California (Lassépas, 1995:376).

del 30 de diciembre de 1836 se decretó que los Territorios de la Alta y Baja California formaran un departamento, subsistiendo esta designación en la Ley de División Territorial expedida por el Congreso General el 30 de junio de 1838. Para el decreto del 22 de agosto de 1846, la Alta y la Baja California son integradas en el estado de las Californias, al entrar en vigor la Constitución de 1824. El 18 de mayo de 1847, el Soberano Congreso Constituyente expidió el Acta Constitutiva y de Reformas de los Estados Unidos Mexicanos, en la cual desaparece el estado de las Californias y se crean dos territorios independientes entre sí: la Alta y la Baja California; sin embargo, esta disposición ya no tenía ningún efecto en la Alta California, la cual estaba tomada por los estadounidenses (INEGI, 1996:51). 
Sin embargo, en su estudio realizado entre 1857 y 1858 , Lassépas tan sólo consignó cuatro casos de adjudicaciones de Pío Pico en el norte de la Baja California, que son: la antigua misión de Guadalupe a Juan Bandini, el 4 de diciembre de 1845; el valle deSan Rafael y Los Vallecitos a Abel Stearns, la segunda concesión el 6 de junio de 1846; y el valle de la Trinidad a Tomás Warner, el 22 de mayo de 1846 (Lassépas, 1995:257265). Resalta que todos estos casos, además del refrendo del título del rancho Tía Juana o Tijuana (AM-IIH, rollo 7, referencia 104), fueron realizados en fechas anteriores al viaje-huida de Pico por el norte de la Baja California, que fue del 7 al 22 de octubre de 1846 (cuadro 1).

Cuadro 1. Títulos de las enajenaciones de terrenos baldíos concedidos en el norte de la Baja California, según información recabada por Urbano Ulises Lassépas, 1857-1858

\begin{tabular}{|c|c|c|c|c|}
\hline Interesados & Terrenos & $\begin{array}{l}\text { Extensión } \\
\text { (sitios) }\end{array}$ & Autoridad & Fecha \\
\hline $\begin{array}{l}\text { María Amparo } \\
\text { de Burton }\end{array}$ & La Ensenada & 5 & Arrillaga & 10 de julio de 1804 \\
\hline $\begin{array}{l}\text { J. Ignacio de Jesús } \\
\text { Arce }\end{array}$ & San Telmo & 1 & Monterde & 15 de enero de 1834 \\
\hline $\begin{array}{l}\text { María Amparo } \\
\text { de Burton }\end{array}$ & San Antonio & 1 & $\begin{array}{l}\text { Ayuntamiento } \\
\text { de Loreto }\end{array}$ & 10 de diciembre de 1834 \\
\hline Herederos Gracianos & San Francisco & 1 & $\begin{array}{l}\text { Luis del Castillo } \\
\text { Negrete }\end{array}$ & 8 de enero de 1838 \\
\hline Agustín Mancilla & Valle de San Rafael & 4 & Miranda & 3 de octubre de 1844 \\
\hline $\begin{array}{l}\text { Antonio Moreno, } \\
\text { Manuel Salvador y } \\
\text { Atanasio Villarino }\end{array}$ & $\begin{array}{l}\text { El valle de las } \\
\text { Palmas }\end{array}$ & 11 & Gómez & 18 de mayo de 1855 \\
\hline
\end{tabular}

Títulos sin noticia pormenorizada y en poder de los interesados

\begin{tabular}{llc}
\hline $\begin{array}{l}\text { Francisco Javier } \\
\text { Gastélum }\end{array}$ & El Vallecito & 1 \\
$\begin{array}{l}\text { Francisco Javier } \\
\text { Gastélum }\end{array}$ & La Ensenada & 2 \\
Ignacio Arce & San Telmo & 1 \\
Ignacio Arce & San José & 1 \\
Domingo Sáinz & Soledad de la Grulla & $1 \frac{1}{2}$ \\
Tomás Bona & Santa Teresa & 1 \\
Estanislao Armenta & San Isidro & 1 \\
Estanislao Armenta & San Antonio & 1 \\
José Luciano Espinosa & San Pedro Mártir & 1 \\
José Luciano Espinosa & San Ramón & 1 \\
José Luciano Espinosa & Santo Domingo & 1 \\
\hline
\end{tabular}

(Continúa...) 
(...continuación)

Cuadro 1. Títulos de las enajenaciones de terrenos baldíos concedidos en el norte de la Baja California, según información recabada por Urbano Ulises Lassépas, 1857-1858

\begin{tabular}{|c|c|c|c|c|}
\hline Interesados & Terrenos & $\begin{array}{l}\text { Extensión } \\
\text { (sitios) }\end{array}$ & Autoridad & Fecha \\
\hline & \multicolumn{4}{|l|}{ (misión) } \\
\hline Eugenio Espinosa & San Simón & 4 & & \\
\hline J.M. Aguiar & Las Ánimas & 1 & & \\
\hline Máximo Sáinz & Santa Gertrudis & 1 & & \\
\hline Guadalupe Meléndrez & Santa Clara & 1 & & \\
\hline Santiago Argüello & Tía Juana & 1 & & \\
\hline Hilario Murillo & Durango & 1 & & \\
\hline Hilario Murillo & San Antonio & 1 & & \\
\hline Pedro Duarte & Rancho Viejo & 1 & & \\
\hline Aniceto Duarte & Arroyo Seco & 1 & & \\
\hline Santiago Domingo Arce & La Berrenda & 1 & & \\
\hline Manuel Manrique & Misión Vieja & 1 & & \\
\hline Manuel Manrique & Santa Rosa & 1 & & \\
\hline Eugenio Murillo & El Salado & $1 \frac{1 / 2}{2}$ & & \\
\hline Juan Bandini & Guadalupe (misión) & ) 4 & Pío Pico & 4 de diciembre de 1845 \\
\hline Abel Stearns & Valle de San Rafael & 3 & Pío Pico & \\
\hline Abel Stearns & Los Vallecitos & 2 & Pío Pico & 6 de junio de 1846 \\
\hline Tomás Warner & Valle de la Trinidad & d 4 & Pío Pico & 22 de mayo de 1846 \\
\hline Carlos Espinosa & Misión del Rosario & 4 & & \\
\hline \multirow[t]{9}{*}{ J. Machado } & Misión del Descanso & so 4 & & \\
\hline & Tecate & 1 & & \\
\hline & El Carricito & 1 & & \\
\hline & La Calentura & 1 & & \\
\hline & San Jacinto & 1 & & \\
\hline & El Pueblito & 1 & & \\
\hline & Jesús María & 1 & & \\
\hline & Puerto Escondido & 1 & & \\
\hline & San Francisco & 1 & & \\
\hline Fco. del Castillo Negrete & Los Álamos & 1 & Rafael Espinosa & 10 de mayo de 1852 \\
\hline Fco. del Castillo Negrete & El Rosarito & 1 & Rafael Espinosa & 10 de mayo de 1852 \\
\hline
\end{tabular}

Fuente: Lassépas, 1995:223-239, 244-247 y 257-264.

Pero además, en el documento Información sobre la enajenación de las misiones de la Frontera de la Baja California elaborado por Francisco del Castillo Negrete con base en interrogatorios a algunos de los propietarios frontereños en 1851 (AD-IIH, Justicia y Negocios Eclesiásticos, 4.46, especialmente f. 1-27), sólo la concesión de la antigua misión de San Fernando adjudicada a Juan Marrón podría caer dentro del periodo 
de la estancia de Pico y Moreno en esa región. Sin embargo, todos los entrevistados reconocieron que fue Pico quien les adjudicó las propiedades respectivas mediante subastas públicas. Por lo que todo indica que en realidad esos títulos fueron cedidos bajo la influencia del decreto de la Asamblea Departamental del 28 de mayo de 1845, y no tanto por la crisis por la invasión estadounidense, es decir, como parte de las intensiones expansionistas de los grupos de poder de la Alta California previos a la invasión estadounidense (cuadro 2).

Por su parte, Pío Pico, en su testimonio entregado en 1877, resalta que "ha llegado a mí noticia que es lo dicho que yo en los últimos días de mi mando en California vendí las misiones, recibiendo por ellas veinte y tantos mil pesos, los mismos que me llevé cuando salí del país [...] Las únicas misiones que vendí fueron San Gabriel, San Luis Rey, San Fernando, San Diego, San Juan Capistrano y San Buenaventura" (Pío Pico, "Narración histórica", en BL, CD, vol. 13:171). No obstante, en otros momentos del testimonial, Pico dio indicios sobre su postura en dos aspectos importantes: uno con relación a la adjudicación de las tierras misionales en general cuando señaló que,

[...] en efecto, ya casi en los últimos días de mi gobierno puse en venta las misiones, logrando salir de algunas por cantidades tan insignificantes que sonroja el mencionarlas. Pero yo estaba determinado a acabar con el sistema de misiones a todo trance, para que los terrenos pudiesen ser adquiridos por particulares, como estaba dispuesto en la ley de colonización.

Y el otro tópico es respecto a la jurisdicción de su mandato: “Pedí a la Asamblea que señalara hasta dónde debía ser la jurisdicción de mi gobierno. Se señaló hasta San Fernando en la Baja California inclusive", es decir el norte de la Baja California (Pío Pico, “Narración histórica", en BL, CD, vol. 13:134 y 130).

No se puede negar que algún dinero de la subasta de las tierras de las antiguas misiones del norte de la Baja California pudo haber sido destinado a los gastos de la guerra, como al parecer ocurrió con el pago de la antigua misión de Santo Domingo: "[Fray Tomás Mansilla] dijo que fue nombrado depositario para recibir el importe del remate por el señor gobernador Pío Pico, quien dijo al hermano del exponen- 


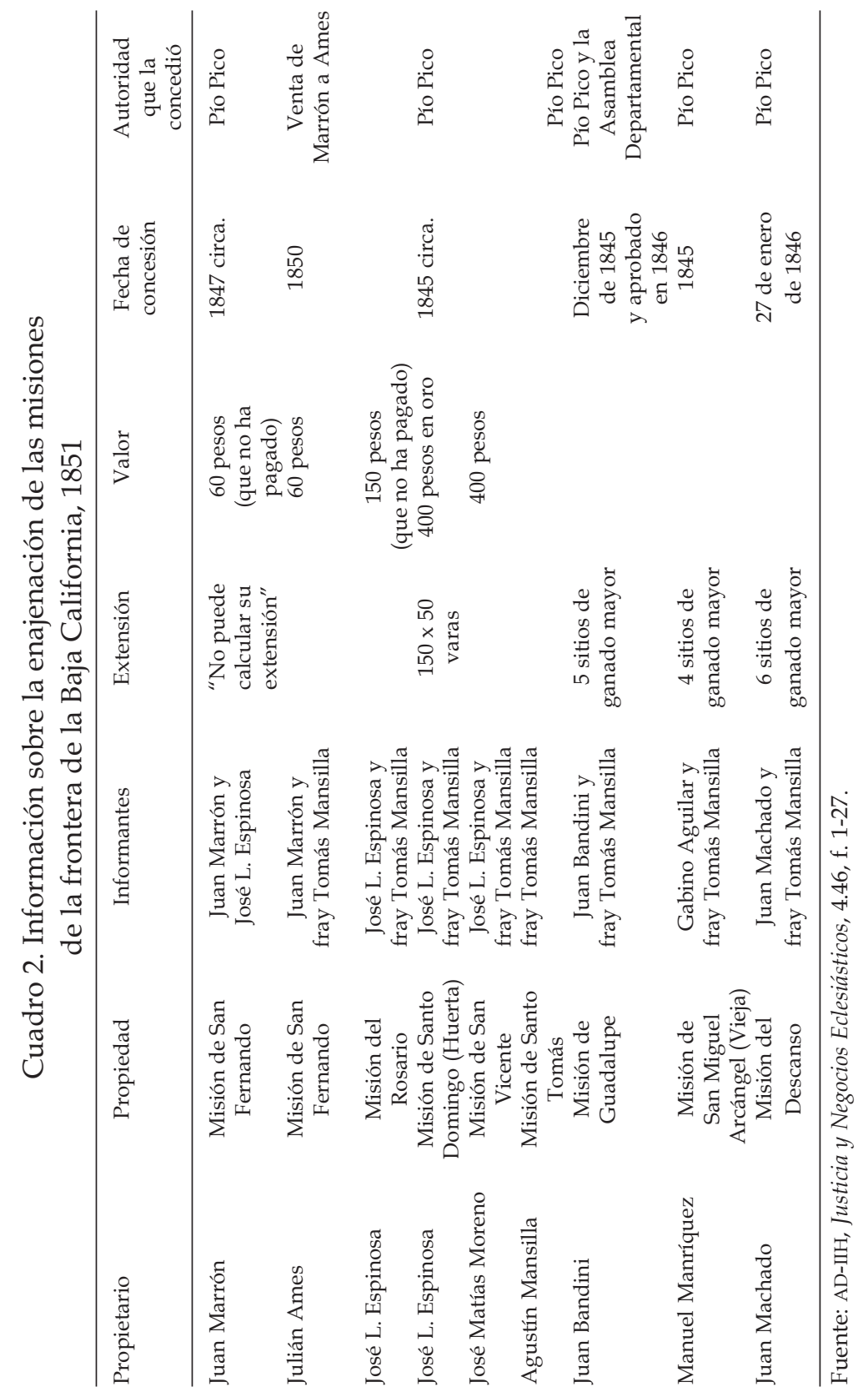


te que los cuatrocientos pesos del importe de Santo Domingo los tomase su hermano don Agustín en pago de las armas que facilitó para la guerra; que de todos los individuos que remataron misiones ninguno ha pagado sino don José Espinosa" (AD-IIH, Justicia y Negocios Eclesiásticos, 4.46, especialmente f. 12-13). Sin embargo, los documentos y testimonios indican más bien una estrategia del grupo de poder de la Alta California, especialmente del sur, por apoderarse de estos bienes en su provecho como parte de su crecimiento con base en los negocios y ranchos establecidos entre los pueblos de San Diego y Nuestra Señora de los Ángeles, y que la invasión y posterior anexión de la Alta California a los Estados Unidos vino a trastocar completamente su vida, incluyendo posesiones, intereses y negocios. Así, la invasión estadounidense a la Alta California (a partir del 7 de julio de 1846), la firma del tratado de Guadalupe Hidalgo (el 2 de febrero de 1848) -que estableció una nueva línea divisoria entre México y los Estados Unidos- y la incorporación del ya para entonces llamado estado de California a los Estados Unidos (el 9 de septiembre de 1850), cambiaron las circunstancias en las cuales los grupos socioeconómicos habían iniciado su consolidación como una élite terrateniente en la Alta California, afectando también el desarrollo del norte de la Baja California.

En cuanto a la República Mexicana y la península de la Baja California, la situación de la pérdida del territorio septentrional (18461848) y su confirmación por el tratado de Guadalupe Hidalgo (1848), motivó una nueva realidad para el gobierno mexicano, llevándolo a la implementación de una política fronteriza abiertamente defensiva. Así, el 19 de julio de 1848, el presidente José Joaquín de Herrera expidió un decreto para la creación de colonias militares, en el cual se incluyó un detallado reglamento para la implementación y buen gobierno de las mismas. Estas disposiciones estaban dirigidas a cumplir dos objetivos primordiales: $a$ ) defender la nueva línea divisoria binacional con elementos armados, y $b$ ) que estos militares fueran a su vez colonos, junto con sus familias; es decir, que iniciaran la explotación de las tierras colindantes con la colonia militar y se fomentaran la ganadería, las artes menores y el comercio (AD-IIH, Gobernación, 7.14 y 16.10). 
De inmediato, la administración de Herrera buscó la persona adecuada para implementar este proyecto en la península de la Baja California, ya que el decreto establecía que una de las colonias militares se ubicaría en la localidad de "Rosales", es decir El Rosario, o mejor dicho la antigua misión de Nuestra Señora del Santísimo Rosario. Las otras colonias militares estarían en Camargo, Guerrero, Monterrey (frente a Laredo), El Pan, Río Grande, Monclova viejo, San Vicente, San Carlos, Pilares, Paso Real, Janos, Baviaspe, Frontera, Santa Cruz, Tucson, Altar, y la citada Rosales en la Baja California (AD-IIH, Gobernación, 16.10). El elegido fue el entonces diputado Rafael Espinoza, quien obtuvo su licencia del Congreso de la Unión el 9 de enero de 1849, y para el 11 de enero fue nombrado de manera oficial por Herrera como "jefe político de la Baja California" (AD-IIH, Gobernación, 7.18, f. 4 y 6). Para el 28 de abril de 1849, estando Espinoza aún en la Ciudad de México, se le hizo llegar el documento Instrucciones para el gobierno de California. Dichas "instrucciones" eran un conjunto de recomendaciones para la administración de la Baja California que reflejan la para entonces nueva situación nacional y los temores post-bélicos del gobierno nacional. Por ejemplo, se señaló que "cuantas menos relaciones, cuanta menos comunicación haya por ahora entre nuestra California y las posesiones americanas, menos riesgo tendremos" (ADIIH, Gobernación, 7.18, f. 32-43, cita p. 34).

El coronel Rafael Espinoza marchó a su encomienda y para el 14 de julio tomó posesión de su cargo, sustituyendo a Nicolás Lastra en La Paz (AD-IIH, Gobernación, 7.18, f. 56). Espinoza contaba con los nombramientos de jefe político y comandante militar de la Baja California, así como el de inspector de las colonias militares de la frontera occidental. Por este último cargo, era la persona comisionada para supervisar y llevar a cabo la colonia militar proyectada para la frontera mexicano-estadounidense en la Baja California. Pero fue a Manuel Castro, antiguo residente de la Alta California, a quien el jefe político le encomendó la implementación de este proyecto. Así, para mediados de agosto de 1849, Manuel Castro, capitán primero de la colonia militar, salió con parte de los hombres rumbo a El Rosario, y José Antonio Chávez, teniente de la colonia militar, se quedó en La Paz, esperando un cargamento de herramientas de labranza para la 
colonia (AM-IIH, rollo 9:138-141). La marcha fue lenta, Castro decía que debido a la falta de recursos y a los precios extraordinarios que los rancheros pedían por el ganado vacuno, pero sobre todo por el caballar. No obstante, es probable que esta lentitud se debiera a que estimó que la empresa era mucho más difícil de lo que había calculado (AM-IIH, rollo 9:268-269). Por fin, para febrero de 1850 llegaron los contingentes de Castro y Chávez a la antigua misión de San Fernando de Velicatá y el 5 de marzo de 1850 pasaron revista a la tropa en la antigua misión de Nuestra Señora del Santísimo Rosario, ya para entonces conocida simplemente como El Rosario (AM-IIH, rollo 9:346, y 350-351). En cuanto llegaron Castro y sus hombres a El Rosario, el capitán inició la búsqueda de un mejor lugar para la colonia militar, encontrándolo en el área de Santo Tomás, a donde trasladó a toda la tropa y acompañantes a finales de julio de 1850, ya que la revista de agosto ya fue realizada en esa localidad (AM-IIH, rollo 9:515-517).

En la cuestión de la tenencia de la tierra, ya para 1849 el propio Castro, con la información que fue recolectando en su traslado hacia el norte de la Baja California, fue percibiendo que la mayoría de los terrenos aprovechables de las antiguas misiones y de los valles interiores habían sido entregados o formalizados a diferentes personas por Pío Pico, entre 1845 y 1846 (AM-IIH, rollo 9:178-182). No obstante, durante el periodo de existencia de la colonia militar, a partir de 1850 y posiblemente hasta 1853 , diversos individuos solicitaron tierras en diferentes lugares, pero la mayoría se ubicó fuera de las zonas tradicionales de las antiguas misiones dominicas, salvo el caso de Santa Catarina, donde por ejemplo solicitaron Ramón Figueroa, José María Ramírez y Gregorio Fraigo, "naturales de Sonora" (AM-IIH, rollo 9:270271), o en regiones poco exploradas de la frontera misional dominica, como al norte de la ensenada de Todos Santos, donde el indio Pascual Domínguez, natural de la antigua misión de San Miguel Arcángel, solicitó autorización para la posesión del "aguaje nombrado de 'Salsipuedes' en el cual tiene una huerta" (AM-IIH, rollo 9:594).

Para el bienio 1850-1851, la gran mayoría de las tierras aprovechables de la zona occidental del norte de la Baja California, desde El Descanso hasta El Rosario, se encontraban adjudicadas o en posesión de hecho de diferentes familias e individuos, principalmente con el aval de 
la administración de Pico, pero también, como se observa en la información recolectada por Lassépas entre 1857 y 1858, un buen número de propiedades estaban clasificadas como "Títulos sin noticia pormenorizada y en poder de los interesados" (cuadro 1). Lo que nos muestra una ocupación informal de los antiguos soldados misionales y sus descendientes de las tierras misionales a partir de 1808 y que, salvo algunos casos, la mayoría no logró formalizar su posesión por la falta de recursos en los momentos en que hubo esa oportunidad, como las subastas impulsadas por Pico, o para realizar las revalidaciones de las concesiones ante el gobierno regional, como lo hicieron familias como los Argüello, Bandini y Machado. La llegada de una autoridad como Castro propició un enfrentamiento con los rancheros frontereños de estrechos vínculos con los sobrevivientes californios sureños. Además, es de recordar que Castro y Chávez eran originarios del área de Monterrey en la Alta California, y al parecer fueron cercanos a los líderes californios "norteños", como José Castro y Mariano Guadalupe Vallejo.

En un primer acercamiento a esta etapa histórica, se puede percibir que después de cerca de 30 años de falta de autoridad en la región (1822-1850), la presencia del capitán Castro como autoridad de facto, y su intensión de regularizar la vida pública y sobre todo la delicada cuestión de la tenencia de la tierra, llevó a enfrentarlo con los rancheros y pequeños propietarios existentes a su llegada, como José Luciano Espinosa (dueño del rancho de Santo Domingo), como el mismo Castro lo expresó en un borrador de informe de 1849:

Los ramos de administración pública se hallan en los pueblos de esta frontera en una completa desorganización. Las disposiciones del supremo gobierno y las del particular del territorio si bien se reciben jamás se sabe se les dé publicidad y menos el debido cumplimiento [...] Ninguno de los funcionarios es debidamente respetado, pero ni tampoco ellos conocen autoridad alguna que las excite siquiera al cumplimiento de sus deberes. Los habitantes de esta frontera han vivido casi siempre en el mayor abandono: anteriormente unos recurrían para sus negocios al gobierno de la Alta California y otros al que siempre ha subsistido en la Baja [...] (AM-IIH, rollo 9:252). 
Tras una serie de enfrentamientos y la salida de Castro del norte de la Baja California, al parecer Francisco del Castillo Negrete pudo instalarse como subjefe político y capitán primero de la colonia militar, entre mediados de 1852 y principios de 1853, en sustitución de Castro. Así, el conflicto por el control de la colonia militar de la Frontera de la Baja California colocó a la región en una difícil situación, que aún no se controlaba de manera completa y satisfactoria cuando William Walker llegó a la región en noviembre de 1853. Así, es revelador lo que el 3 de diciembre de 1853 José Antonio Chávez le escribió a Manuel Castro, desde San Diego, comunicándole que

[...] la Baja California hoy día es nueva república y que mi querido padrino [Rafael Espinosa] está en Santo Tomás como prisionero voluntario según la voz pública, a las órdenes del comandante [William Walker] que desembarcó hace cuatro días ocupando la Frontera. Amigo, creo que ya la cosa comenzó a llevársela el diablo (AM-IIH, rollo 10:600).

En la última etapa de la historia de los frontereños, entre 1850 y 1870, después del duro golpe a la economía regional y a la inseguridad pública provocado por los conflictos entre las autoridades de hecho y de derecho de la colonia militar (1850-1852), la crisis filibustera de William Walter (1853-54), y la nueva lucha por el poder contra Antonio María Meléndrez (1854-55) (Valadés, 1974:48), sumió a la región del norte de la Baja California en un caos, siendo los más afectados los pobladores no indígenas que migraron hacia el refugio del área de San Diego (Alric, 1995:110), bajo la protección de la comandancia militar estadounidense acuartelada en ese poblado. Pero también entre 1856 y 1860 se continuaron los enfrentamientos entre los frontereños y algunos funcionarios designados por las autoridades mexicanas o peninsulares como José Castro, Francisco de Paula Ferrer y José Matías Moreno. Para finales de 1860 y principios de 1861, este último al ver declinar su influencia frente a la de José Castro y Feliciano R. Esparza, decidió buscar ayuda en el gobierno peninsular, bajo el argumento de que Castro y Esparza buscaban separar el norte de la Baja California de la República Mexicana y adherirla a la California estadounidense. Pero uno de los motivos fundamentales fue la lucha por la 
apropiación de los terrenos que pudieran ser ofrecidos a colonos y especuladores en la región, que Castro, y en parte Esparza, estaban distribuyendo (cuadros 3 y 4). Así, Moreno logró imponerse por la fuerza con un numeroso contingente traído desde Sinaloa (Alric, 1995:120-121).

En relación con la reglamentación sobre la tenencia de la tierra, entre 1850 y 1870 se dieron algunas disposiciones por el gobierno territorial, entre ellas, la más importante fue el denominado Decreto por el cual se declaran colonizables las tierras de las extinguidas misiones, expedido por la Diputación Territorial de la Baja California y publicado por Rafael Espinoza el 12 de febrero de 1851, en el cual se declararon "colonizables las tierras de las extinguidas misiones", ya sin la consabida excepción para la región del norte de la Baja California, como fue costumbre en todas las disposiciones emitidas desde las autoridades peninsulares hasta esa fecha. El artículo $8^{\circ}$ estableció que "los terrenos que se colonizaren en la Frontera, serán libres por diez años de pagar a la hacienda territorial los derechos de que hablan los artículos $2^{\circ}$ y $5^{\circ}$, entendiéndose por Frontera desde El Rosario hasta la línea divisoria de la Alta California" (Lassépas, 1995:370-373).

También entre 1850 y 1870 se dieron algunas disposiciones por parte de las autoridades mexicanas sobre la tenencia de la tierra, que al parecer poco pesaron en el norte de la Baja California, inmerso en su propia dinámica sociopolítica, pero que motivaron lo que para Manuel Castro y Francisco del Castillo Negrete era evidente en 1850, es decir, que existían muchas posesiones no formalizadas de las tierras aprovechables, principalmente en la zona occidental, donde se desarrollaron las misiones franciscanas y dominicas. Para Sonora, aunque las disposiciones fueron anteriores al periodo de 1850-1870, también tuvieron el efecto de evidenciar a los poseedores de tierras sin títulos legales desde la perspectiva de la autoridad del supremo gobierno o de los gobiernos estatales (Romero, 1995:195). Lo que nos muestra una tendencia nacional y regional que a fin de cuentas tocó al norte de la Baja California. Así, la primera reglamentación fue expedida por Ignacio Comonfort y se denominó Decreto que las ventas o enajenaciones de las islas o terrenos baldios de la Baja California que se hubieren hecho desde 1821 hasta el presente son nulas mientras no obtengan la ratificación del supremo gobierno, mejor conocida como la Ley del 10 de marzo de 1857, 


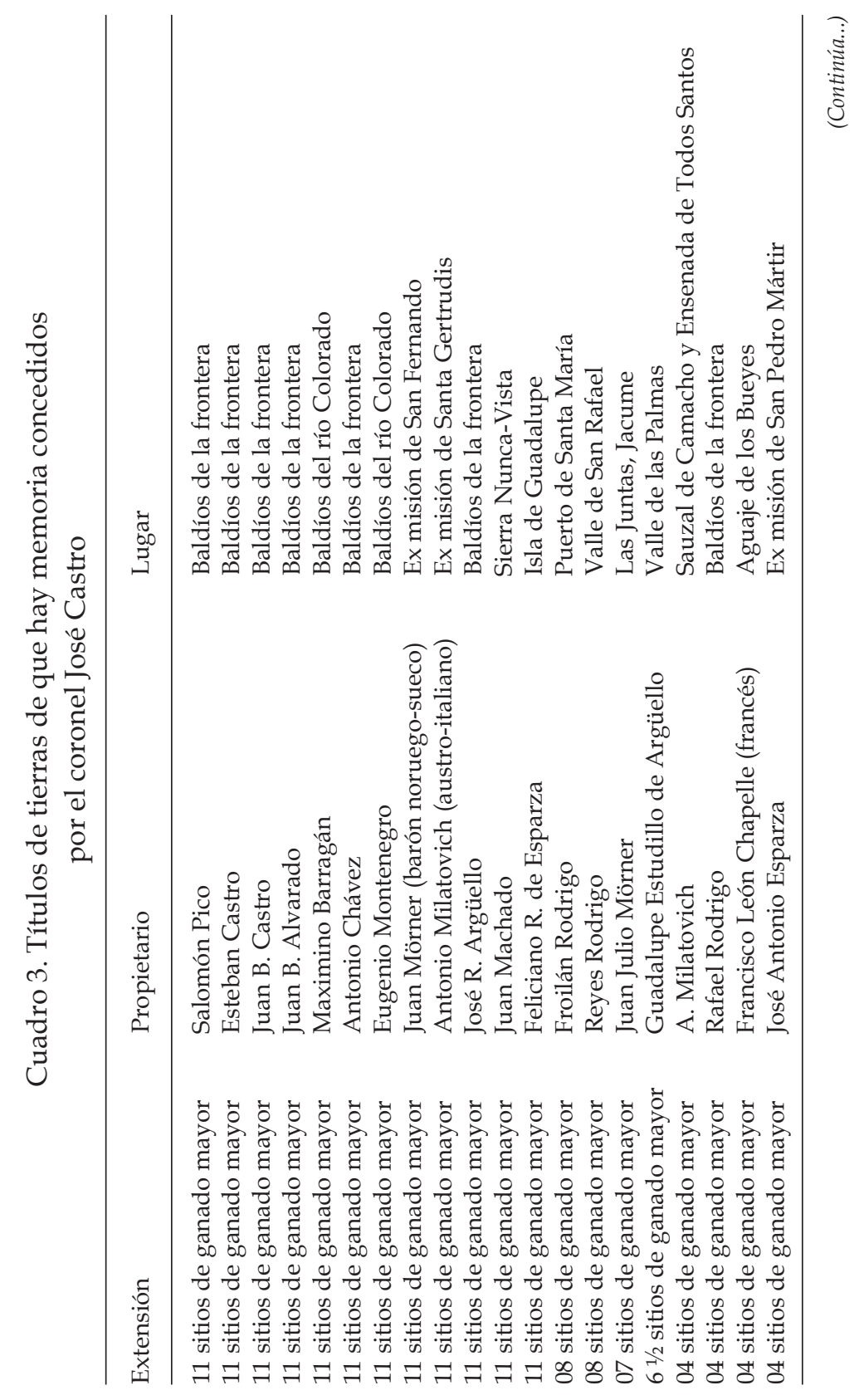




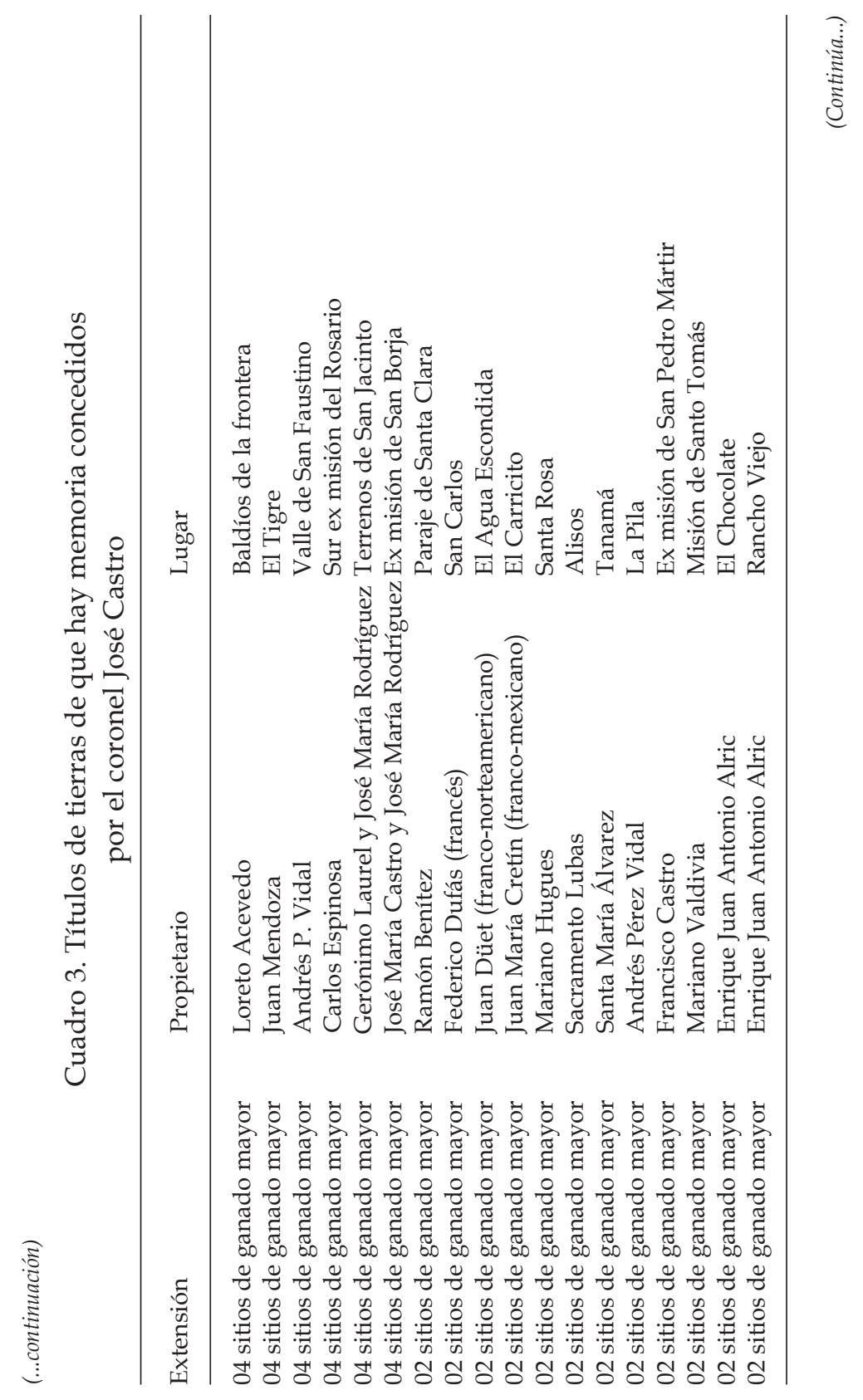




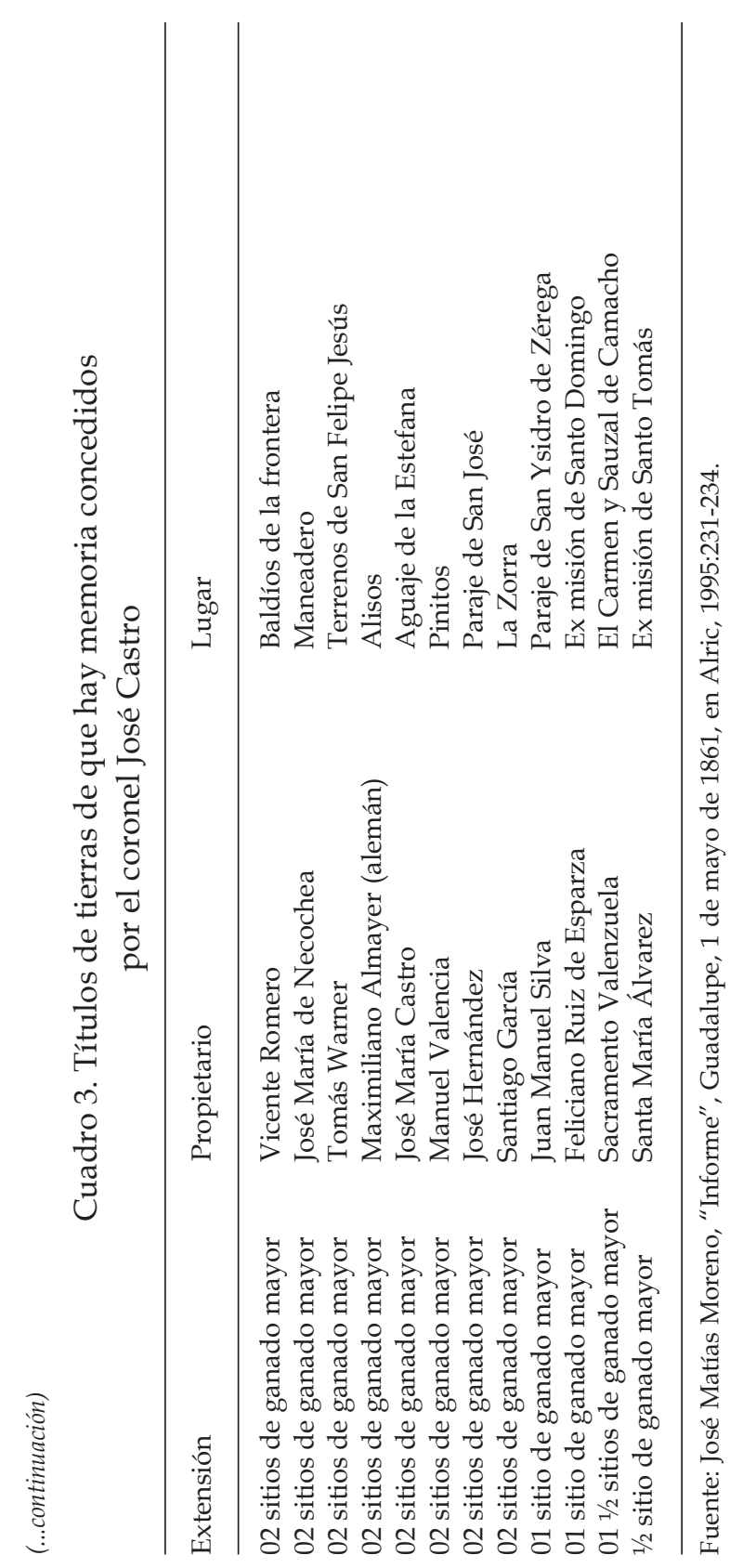


Cuadro 4. Concesiones de tierras hechas en la frontera por el ciudadano Feliciano Ruiz de Esparza de que hay noticia

\begin{tabular}{|c|c|c|}
\hline Extensión & Propietario & Lugar \\
\hline 08 leguas cuadradas & Mariano Valdivia & Terrenos del río Colorado \\
\hline 04 leguas cuadradas & $\begin{array}{l}\text { Enrique Juan } \\
\text { Antonio Alric }\end{array}$ & Tierras del río Colorado \\
\hline 04 sitios de ganado mayor & $\begin{array}{l}\text { Gerónimo Laurel } \\
\text { y José María Rodríguez }\end{array}$ & Arrastradero \\
\hline 02 leguas cuadradas & $\begin{array}{l}\text { Sonorenses Martínez } \\
\text { y Espinosa }\end{array}$ & Tierras del río Colorado \\
\hline 02 leguas cuadradas & José María Castro & Terrenos del río Colorado \\
\hline 01 sitio de ganado mayor & Juan Manuel Silva & Terrenos de San Vicente \\
\hline 01 sitio & Mariano Valdivia & Terrenos de San Vicente \\
\hline
\end{tabular}

Fuente: José Matías Moreno, “Informe”, Guadalupe, 1 de mayo de 1861, en Alric, 1995: 235-236.

que motivó la revisión general y detallada de la situación de la tenencia de la tierra en la Baja California, donde fue conocida hacia finales de ese mismo año. Que a su vez llevó a la realización del memorial realizado por Urbano Ulises Lassépas (1995; Piñera, 1991b). Por su parte, para el 14 de marzo de 1861 Benito Juárez ratificó lo dispuesto por Comonfort al emitir el Decreto que considera nulas todas las enajenaciones realizadas por cualquier autoridad sin el consentimiento del gobierno general. Estos decretos estimularon la cada vez mayor presencia del gobierno nacional en el norte de la Baja California, que se vendrá a reforzar con el apoyo militar a José Matías Moreno y su posesión como subjefe político en esta región para 1861 (AD-IIH, Gobernación, 16.62).

\section{Conclusiones}

De manera general podemos establecer que además de los grupos indígenas existieron dos grupos sociales no indígenas dentro del devenir histórico y demográfico que se deben tomar en cuenta para el estudio de estas sociedades entre 1769 y 1870, en el norte de la Baja California. El primero es el de los misioneros, principalmente dominicos, que aunque numéricamente no fueron considerables, sí lo fueron 
como intermediarios entre los indígenas, y los segundos, especialmente los soldados misionales, mayordomos, sirvientes, sus familias y descendientes, que después se constituyeron en la sociedad ranchera frontereña de mediados del siglo XIX.

En el norte de la Baja California entre 1769 y 1870 tenemos un proceso de creación de un grupo social que inició con los soldados misionales, que de manera formal dependían del presidio de Loreto pero en la práctica se vincularon estrechamente con las misiones y sus temporalidades, y al momento de las dificultades para obtener sus sueldos y avituallamientos entre 1808 y 1822, cada vez fue mayor su dependencia de los recursos de las misiones, las cuales en ese momento empezaban a ser productivas dentro de sus circunstancias. Pero ante la disyuntiva de a quién se debería dar prioridad en el acceso a los recursos de supervivencia, se considera que a partir del inicio del siglo XIX se fue estructurando una estrategia de expulsión o no atracción de gentiles para poder cubrir las necesidades de los soldados misionales, los mayordomos, los sirvientes, los indios de casa y sus familias, además del misionero.

Además, para la primera mitad del siglo XIX cada vez fue más difícil lograr el reemplazo de los misioneros dominicos y así, para 1840, fray Tomás Mansilla era el único que atendía a los feligreses e indígenas que habitaban todo lo que hoy es el estado de Baja California. Por su parte, los frontereños y los neófitos fueron usufructuando las huertas, sementeras y tierras de pastoreo en su propio provecho, hasta que después de 1822, con la presencia del enviado imperial, quedó claro que nada volvería a ser como antes. Así, del usufructo temporal se pasó a la posesión de hecho de las tierras misionales, surgiendo lo que para la década de los cincuenta del siglo XIX se empezó a denominar como los "frontereños".

El estudio de los frontereños a través de aquellos que pudieron obtener tierras, nos muestra que son parte fundamental de la comprensión de la historia del norte de la Baja California para los siglos XVIII y XIX. Estos rancheros deben ser comprendidos como parte de esa historia regional en zonas de desierto que buscaron su supervivencia ante la carencia de alternativas, pero no se debe caer en una idea de una élite económica, social y política, sino en grupos de poder 
en formación con intereses muy concretos, lejos de esos mitos de los Silver Dons de Pourade o los "caudillos" de Sandos en relación con los californios (1998:217-218). Aunque es muy claro que los rancheros frontereños del norte de la Baja California estuvieron estrechamente vinculados con los rancheros, comerciantes y funcionarios de la Alta California, especialmente del área de San Diego y Los Ángeles.

\section{Acervos}

AD-IIH, Acervo Documental del Instituto de Investigaciones Históricas de la Universidad Autónoma de Baja California, en la ciudad de Tijuana. Una de sus principales colecciones consiste en fotocopias de documentos del Archivo General de la Nación, en la Ciudad de México, referentes a las Californias.

AM-IIH, Acervo de Microfilmes del Instituto de Investigaciones Históricas de la Universidad Autónoma de Baja California, en la ciudad de Tijuana. Entre sus colecciones se encuentran documentos microfilmados procedentes de la Biblioteca Bancroft (BL), en la ciudad de Berkeley y del sistema Universidad de California.

BL, Biblioteca Bancroft en la ciudad de Berkeley y del sistema Universidad de California, en donde se consultaron algunos documentos originales del siglo XIX que no se encuentran en el AM-IIH, especialmente los fondos de testimonios y de la Alta California.

\section{Bibliografía}

Alric, Henry J. A. (1995), Apuntes de un viaje por los dos océanos, el interior de América y de una guerra civil en el norte de la Baja California, colección Baja California: Nuestra Historia, núm. 9, Secretaría de Educación Pública y Universidad Autónoma de Baja California, Mexicali.

Castillo, Pedro G. y Antonio Ríos Bustamante (1989), México en Los Ángeles. Una historia social y cultural, 1781-1985, Alianza, Conaculta, México. 
Del Río Ignacio y María Eugenia Altable Fernández (2000), Breve historia de Baja California Sur, El Colegio de México, Fideicomiso Historia de las Américas, Fondo de Cultura Económica, México.

Engelhardt, fray Zephyrim (1929), The Missions and Missionaries of California, vol. 1, Lower California, Santa Bárbara Mission, Santa Bárbara.

Engstrand, Iris H. W. (1980), San Diego: California's Cornerstone, Continental Heritage Press, Tulsa.

Giménez, Gilberto (2004), “Culturas e identidades”, Revista Mexicana de Sociología, número especial, octubre, pp. 77-99.

Gómez Canedo, Lino (1993), Evangelización, cultura y promoción social, selección de José Luis Soto Pérez, Porrúa, México.

Haas, Lisbeth (1995), Conquests and Historical Identities in California, 17691936, University of California Press, Berkeley.

INEGI (1996), División territorial del estado de Baja California de 1810 a 1995, Instituto Nacional de Estadística, Geografía e Informática, México.

Landavazo Arias, Marco Antonio (2003), “Federalismo y centralismo: orden institucional y conflicto político", en Edith González Cruz, (coord.), Historia general de Baja California Sur. II. Los procesos politicos, Universidad Autónoma de Baja California Sur, La Paz.

Lassépas, Ulises Urbano (1995), Historia de la colonización de la Baja California y decreto del 10 de marzo de 1857, colección Baja California: Nuestra Historia, núm. 8, Secretaría de Educación Pública, Universidad Autónoma de Baja California, México.

León-Portilla, Miguel y José María Muriá (1992), Documentos para el estudio de California en el siglo XIX, Futura Editores, México.

Lightfoot, Kent G. (2005), Indians, Missionaries, and Merchants. The Legacy of Colonial Encounters on the California Frontiers, University of California Press, Berkeley.

Martínez Zepeda, Jorge (2001), “José Manuel Ruiz, un soldado californiano en la transición de la Colonia al México independiente, 1755-1825", tesis de maestría, Universidad Autónoma de Baja California Sur, La Paz. 
Martínez Zepeda, Jorge (2002), “Fundación de ranchos y colonización civil en la frontera, 1822-1848”, en Catalina Velázquez Morales (coord.), Baja California: un presente con historia, dos tomos, Universidad Autónoma de Baja California, Mexicali.

Mathes, W. Michael (1977), Las Misiones de Baja California/The Mission of Baja California: 1639-1849, Gobierno del Estado de Baja California Sur, La Paz.

Meigs, Peveril (1994), La frontera misional dominica en Baja California, colección Baja California: Nuestra Historia, núm. 7, Secretaría de Educación Pública, Universidad Autónoma de Baja California, México.

Ortega Noriega, Sergio (1993), Un ensayo de historia regional. El noroeste de México, 1530-1880, Universidad Nacional Autónoma de México, México.

Ortega Soto, Martha (2001), Alta California: una frontera olvidada del noroeste de México, 1769-1846, Universidad Autónoma Metropolitana, Plaza y Valdés, México.

Ortiz Figueroa, Jesús (1989), "Rosarito”, en David Piñera Ramírez y Jesús Ortiz Figueroa, Historia de Tijuana, 1889-1989, tomo 1, Universidad Autónoma de Baja California, Tijuana.

Padilla Corona, Antonio (2007), Inicios urbanos del norte de Baja California. Influencias e ideas, 1821-1906, Universidad Autónoma de Baja California, Mexicali.

Palou, fray Francisco (1994), Cartas desde la peninsula de California (17681773), transcritas y editadas con algunas notas y cuatro apéndices documentales por José Luis Soto Pérez, Porrúa, México.

Piñera Ramírez, David (1991a), Historia de la colonización y la política nacional de colonización, Universidad Autónoma de Baja California, Gobierno del Estado de Baja California, Grupo Cultural Septentrión, Tijuana.

(1991b), Ocupación y uso del suelo en Baja California. De los grupos aborígenes a la urbanización dependiente, Universidad Nacional Autónoma de México, México.

Piñera Ramírez, David y Jesús Ortiz (1989), "Primeros pobladores y época misional", en David Piñera Ramírez y Jesús Ortiz Figueroa, Historia de Tijuana, 1889-1989, tomo 1, Universidad Autónoma de Baja California, Tijuana. 
Pourade, Richard F. (1966), The Silver Dons, The Union-Tribune Publishing Company, San Diego.

Radding, Cynthia (1997), Wandering Peoples. Colonialism, Ethnic Spaces and Ecological Frontiers in Northwestern Mexico, 1700-1850, Duke University Press, Durham.

Robinson, W.W. (1979), Land in California. The Story of Mission Lands, Ranchos, Squatters and Mining Claims, University of California Press, Berkeley.

Romero, Saúl Jerónimo (1995), De las misiones a los ranchos y haciendas. La privatización de la tenencia de la tierra en Sonora, 1740-1860, Gobierno del Estado de Sonora, Hermosillo.

Romero Navarrete, Lourdes (1990), “Cuatro documentos históricos sobre Tecate", Meyibó, Segunda época, vol. 1, núm. 1, julio-diciembre, pp. 55-56.

Sandos, James A. (1998), "Between Crucifix and Lance: Indian-White Relations in California, 1769-1848", en Ramón A. Gutiérrez y Richard J. Orsi (eds.), Contested Eden. California before the Gold Rush, University of California Press, Berkeley.

Santiago, Mark (1998), Massacre at the Yuma Crossing. Spanish Relations with the Quechans, 1779-1782, University of Arizona Press, Tucson.

Trejo Barajas, Dení (2002), “Los actores económicos”, en Dení Trejo Barajas (coord.), Historia general de Baja California Sur. I. La economía regional, Universidad Autónoma de Baja California Sur, Secretaría de Educación Pública, Conacyt, Plaza y Valdés, La Paz.

Treviño Calderón, Hesiquio (1982), “José Manuel Ruiz, primer propietario de el paraje de la ensenada de Todos Santos", en Ángela Moyano de Guevara y Jorge Martínez Zepeda (coords.), Visión histórica de Ensenada, Fonapas, CIH-UNAM, UABC, Mexicali.

Valadés, Adrián (1974), Historia de la Baja California, 1850-1880, Universidad Nacional Autónoma de México, México.

Velasco, Emilio (1893), Apuntes del informe pronunciado en 1892 por el licenciado Emilio Velasco, en el juicio promovido por la señora Amparo Ruiz de Burton contra la Compañía Internacional de México, sobre dominio de los terrenos de la Ensenada, Baja California, Tipografía Avenida Juárez núm. 624, Ciudad de México. 
ESTUdIOS FRONTERIZOS, VOL. 10, NÚM. 19, ENERO-JUNIO 2009

Vernon, Edgard W. (2002), Las misiones antiguas. The Spanish Missions of Baja California, 1683-1855, Viejo Press, Santa Bárbara.

Recibido en junio de 2008 Aprobado en octubre de 2008 